\title{
Gradhiva
}

GRADHIV

Revue d'anthropologie et d'histoire des arts

$7 \mid 2008$

Le possédé spectaculaire

\section{Réponse de Roger Bastide à Michel Leiris}

\section{(2) OpenEdition}

1 Journals

Édition électronique

URL : http://journals.openedition.org/gradhiva/1074

DOI : 10.4000/gradhiva.1074

ISSN : 1760-849X

Éditeur

Musée du quai Branly Jacques Chirac

Édition imprimée

Date de publication : 15 mai 2008

Pagination : 68-69

ISBN : 978-2-915133-86-8

ISSN : 0764-8928

Référence électronique

«Réponse de Roger Bastide à Michel Leiris », Gradhiva [En ligne], 7 | 2008, mis en ligne le 15 mai 2011, consulté le 24 avril 2019. URL : http://journals.openedition.org/gradhiva/1074 ; DOI : 10.4000/

gradhiva. 1074

(c) musée du quai Branly 


\title{
Réponse de Roger Bastide à Michel Leiris
}

L

ors de la mission Dakar-Djibouti, Michel Leiris a pu observer directement le culte des zar, ces esprits qui possèdent leurs adeptes dans certaines circonstances rituelles. Ces cérémonies festives et les impressions personnelles de Leiris face aux possédés sont décrites sous la forme particulière du journal dans L’Afrique fantôme (Paris, Gallimard, 1934). En 1958, Michel Leiris publie La Possession et ses aspects théâtraux chez les Éthiopiens de Gondar (Paris, Plon), ouvrage d'une nature différente où il reprend en les théorisant les données collectées en Éthiopie sur la possession. C'est la même année qu'est édité Le candomblé de Bahia (rite nagô) (Paris, La Haye, Mouton, 1958) de Roger Bastide, spécialiste du Brésil et des religions d'origine africaine implantées dans ce pays. Il s'agit de religions dans lesquelles la possession tient un rôle central, tout comme dans le vodou haïtien que Leiris a aussi approché. Leiris envoie donc un exemplaire de La Possession et ses aspects théâtraux... à Bastide ; c'est la lettre de remerciement de Bastide à Leiris que nous publions ici. Ce document nous a été transmis par Jean Jamin, à qui nous exprimons notre gratitude.

\section{ÉCOLE PRATIQUE DES HAUTES ÉTUDES}

\author{
$\left(\mathrm{VI}^{\mathrm{E}} \mathrm{SECTION}\right)$
}

Sciences Économiques et Sociales
17, Rue de la Sorbonne (ODÉon 24-13)

\author{
PARIS, le 15 Mai 1958
}

\section{SORBONNE}

Cher Monsieur,

\begin{abstract}
Ce n'est que maintenant que j'ai pu trouver un moment pour lire votre livre.
Vous savez combien ces problèmes m'intéressent et je vous remercie donc vivement de votre si aimable envoi. Vos précédentes études sur les Zâr m'avaient d'ailleurs particulièrement frappé et dans mon livre brésilien, Imagens misticas..., j'avais donné mon adhésion à votre thèse sur le « vestiaire de personnalités » qui me paraissait devoir s'appliquer à l'Amérique comme à l'Afrique.

Vous me permettrez de vous signaler un certain nombre de faits qui peuvent vous intéresser, dont je ne tire pour le moment aucune conclusion, que je livre seulement à vos réflexions

$1^{\circ}$ ) Le caractère esthétique des «possessions » au Brésil est indéniable ; on pourrait dire qu'elles ont constitué au $\mathrm{XIX}^{\mathrm{e}}$ siècle le théâtre des pauvres et qu'elles le continuent dans le sertão de Bahia encore aujourd'hui. Le Dr. René Ribeiro à Recife a insisté sur cet aspect et moi-même, pour Bahia, dans un article de revue, il me serait facile de vous donner également toute une série d'exemples qui justifient votre suggestion de la p. 100 : « quelque chose de fondamental qui tend à croître en importance ». Mais j' ajouterai, pour le Brésil uniquement pour les sectes en voie de désagrégation, le sacré ne peut donner lieu au théâtre que lorsque la foi au sacré commence déjà à se perdre. $2^{\circ}$ ) Un élément peut être utile pour les rapports entre le « vécu» et le « joué ». Il y a deux sortes de crises mystiques ; celles du rituel de l'initiation, celles de l'entrée du Dieu dans le corps, qui sont brutales et inconscientes - mais après, le prêtre calme le Dieu et le fidèle revient danser dans un état de « demi-extase », comme les fidèles le disent parfois, et qui n'est plus d'inconscience complète. D'ailleurs toute cette psychologie des états de possession reste à faire. On pourrait peut-être organiser un colloque là-dessus avec des psychologues, des psychiatres et des ethnographes. $\left.3^{\circ}\right) \mathrm{Si}$ je compare les faits éthiopiens avec les faits brésiliens, je noterai que la possession par les Zâr ressemble plutôt aux cultes du catimbó qui sont d'origine indienne qu'aux cultes du candomblé d'origine africaine. J'ai donné dans mon livre « Brésil, terre des contrastes » une idée sommaire de ce catimbó, caractérisé par les possessions multiples (alors que dans le candomblé chaque fidèle ne reçoit qu'un Dieu) - et la liaison des Esprits que l'on reçoit avec un besoin de nature individuelle : magie d'amour, guérison d'une maladie, etc. (alors que dans le candomblé l'appel aux divinités correspond à une nécessité communautaire).

Le culte des Vodous me semble former une transition entre les deux. Comme je l'ai dit souvent : le candomblé est une religion « en conserve », donc fidèle à l'Afrique occidentale, le Vodou est une religion " vivante » cad. qui évolue et elle a évolué dans le sens de la perte des mythes collectifs qui sont remplacés par des mythes individuels (les histoires des fidèles possédés donnent lieu à une mythologie de remplacement).
\end{abstract}


De tout cela, ne pourrait-on pas conclure que

a) la possession des peuples non acculturés est essentiellement liée à la vie sociale. Chaque divinité régit un domaine du cosmos et il est nécessaire que la société contrôle ces divers domaines pour le « bien commun ». La possession répond à une nécessité sociologique

b) avec le contact des civilisations, des religions, la possession tend à s'individualiser, et doublement : d'abord elle devient une réponse à des besoins individuels et non plus au « bien commun » - en outre chaque possession s'inscrit dans une psychanalyse plus que dans une mythologie traditionnelle

c) peut-être pourrait-on partir de là pour distinguer le chamanisme de la possession (bien que la distinction classique reste que le chamanisme est une série de visions : ascension dans le ciel pour lutter contre les Espritset que la possession soit une entrée des Dieux dans l'individu)

d) l'évolution que j'indique serait comme celle de votre p.100 non « un élément adventice » mais " quelque chose de fondamental qui tend à croître en importance ». je n'oublie pas en effet la phrase d'un vieux Babalaồ à Maupoil « le désir de chacun, voilà ce qu'est un Vodoum ». Malgré tout, je crois qu'à propos des Zâr comme à propos du catimbó on peut bien parler de désagrégation, en ce sens que la possession africaine est, sous sa forme traditionnelle, « un phénomène total » et que sous sa forme acculturée, ce phénomène se divise en ses éléments ; ou, si vous préférez, pour reprendre une expression de Lévi-Strauss, le «système » se brise pour donner naissance à un chaos d'attitudes individuelles. Je crois que la sorcellerie du Moyen-Age nous donnerait une solution analogue, elle est le dernier moment du " paganisme » acculturé au contact du christianisme (malheureusement nous ne la connaissons que par ses adversaires qui ont laissé échapper beaucoup des éléments de cette sorcellerie, en particulier sa liaison avec des lignages, qui subsiste pourtant encore, comme j'ai pu m'en rendre compte, aujourd'hui dans mes Cévennes)

Excusez moi cette longue lettre. Veuillez y voir seulement le témoignage de la passion avec laquelle j'ai lu votre beau livre. Encore merci et croyez moi bien sincèrement votre,

R. Bastide.
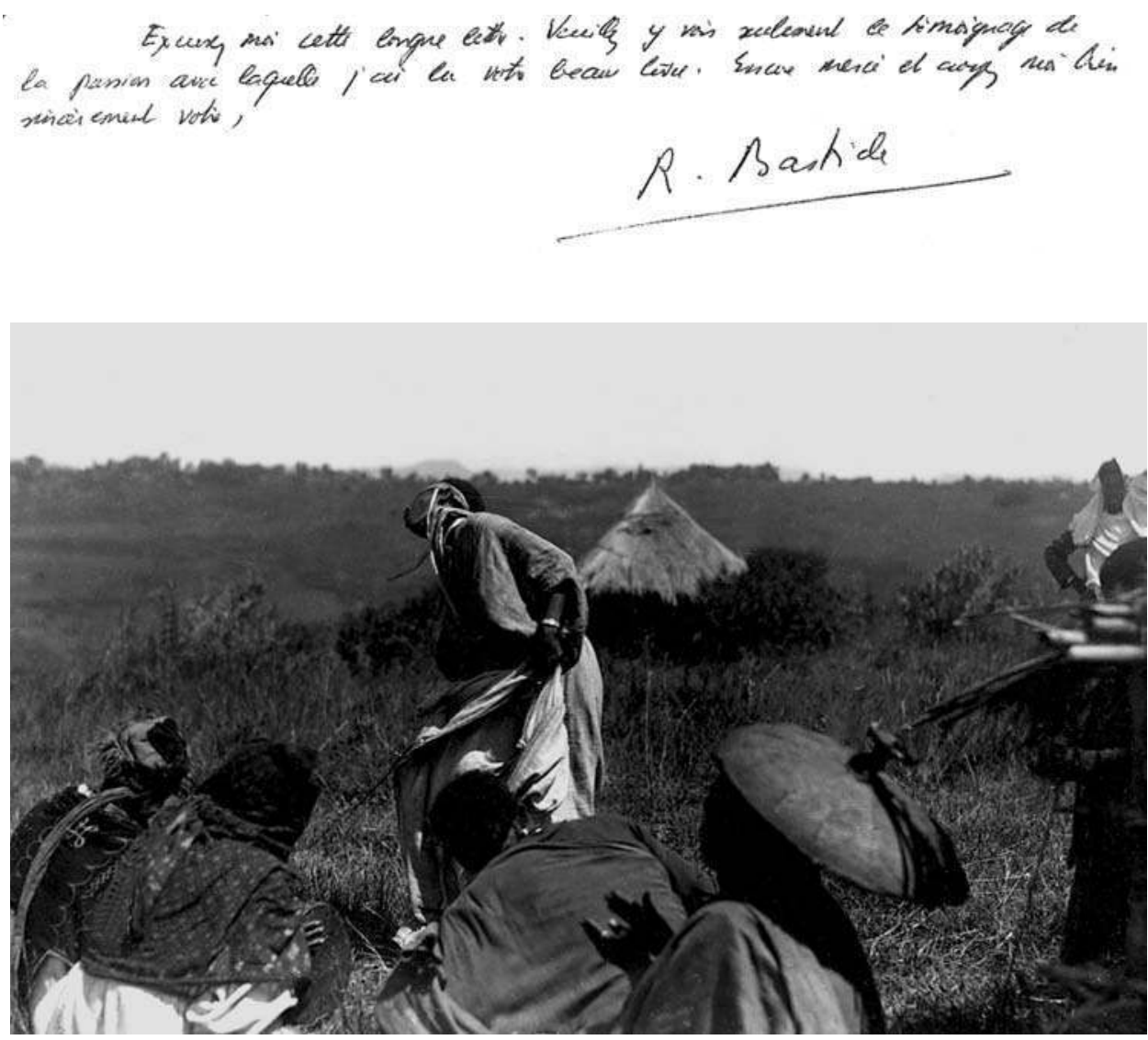

Marcel Griaule, Possédée en transe le lendemain de la Masqal (fête de la croix), Gondar, province de Bagemder, Éthiopie, mission Dakar-Djibouti, 27 septembre 1932. @ musée du quai Branly, photo M. Griaule. 